\title{
La prestación por desempleo y por cese de actividad para los socios trabajadores y de trabajo de las cooperativas
}

\author{
Francisco Javier Sanz Santaolalla
}

Sumario: Introducción. I. La prestación por desempleo en las cooperativas adscritas al Régimen General de la Seguridad Social: 1.1. Regulación. 1.2. Supuestos de desempleo que dan lugar a la prestación por desempleo a los socios trabajadores o de trabajo de las cooperativas y forma de acreditarlas para no perjudicar dicha prestación. 1.3. Impresos. 1.4. Sentencias de interés sobre esta materia. 1.5. Recomendaciones para mejorar la regulación de la prestación por desempleo de los socios trabajadores o de trabajo de las cooperativas. II. La prestación por cese de actividad a los socios de las cooperativas de trabajo asociado encuadrados en el Régimen Especial de los Trabajadores por Cuenta Propia o Autónomos o en el Régimen Especial de los Trabajadores Del Mar: 2.1. Normativa reguladora. 2.2. Prestaciones. 2.3. Supuestos legales de cese de actividad y acreditación de los mismos. 2.4. Requisitos de los socios para tener derecho a las prestaciones. 2.5. Duración de la prestación económica. 2.6. Base reguladora y cuantía de la prestación económica. 2.7. Supuesto que no tiene la consideración legal de cese de actividad y efectos. 2.8. Plazos para realizar la solicitud. 2.9. Cumplimiento de garantías y de procedimientos por parte de la cooperativa. 2.10. Tipo de cotización. 2.11. Jurisdicción competente. 2.12. Recomendaciones para mejorar la regulación de la prestación por cese de actividad los socios trabajadores. III. Anexo de reseñas de sentencias de interés sobre la prestación por desempleo.

Resumen: La presente colaboración tiene por objeto, de una parte, el analizar y detallar los supuestos de la prestación por desempleo, así como sus requisitos, para los socios trabajadores de las Cooperativas de Trabajo Asociado, que estén adscritos al Régimen General de la Seguridad Social y la de los socios de trabajo de otras clases de Cooperativas. Y por otra parte se centra en las prestaciones por cese de actividad, para los socios trabajadores de las Cooperativas de Trabajo Asociado, que hayan optado para sus socios trabajadores por el Régimen Especial de Trabajadores Autónomos. Asimismo, se relacionan los requisitos y las formas en que deben acreditarse cada uno de los 
supuestos que dan lugar a la prestación por desempleo, ya sea por el cese definitivo del socio trabajador o de trabajo en la Cooperativa o por el cese temporal o parcial. Y de idéntica manera se abordan los supuestos por cese de actividad. Por último se realizan recomendaciones para la mejora de la regulación de las citadas materias.

Palabras clave: situación legal de desempleo, situación legal de cese de actividad, socios trabajadores y de trabajo, Régimen General y Régimen Especial de Trabajadores Autónomos.

Abstract: This article focuses on analysis and detailed description of the conditions for unemployment benefits as well as the requirements for worker members of associated cooperatives who are covered by the General Scheme of the Social Security System and for partners in other types of cooperatives. It also examines the benefits in case of termination of activity for worker members of associated work cooperatives which have chosen the Special Scheme for Self-Employed Workers. It offers a list of the requirements and ways in which each of the cases must be verified to determine eligibility for unemployment benefits, either due to a worker member's termination of contract or the cooperative's temporary or partial cessation of activities. The study also examines conditions regulating cessation of activity. Lastly, recommendations on improving regulation are included.

Key words: legally recognised unemployment, legally recognised cessation of activity, Worker members and partners, General Scheme of the Social Security System and Special Scheme for Self-Employed Workers. 


\section{Introducción}

Con el presente artículo se pretende facilitar a los operadores jurídicos de las Cooperativas y a los socios trabajadores de las mismas el itinerario que tienen que seguir, en los diferentes supuestos en los que pueden acceder a la prestación por desempleo, en el caso de estar adscritos al Régimen General de la Seguridad Social, así como a las prestaciones por el cese de actividad en el caso que estén adscritos al Régimen Especial de Trabajadores Autónomos y tengan la cobertura de Accidentes de Trabajo y Enfermedad Profesional, lo que a su vez les obliga a tener la cobertura del cese de actividad.

No pretendemos nada más que facilitar a los lectores la forma de operar en los mencionados supuestos, con el propósito final de evitar que se perjudiquen o se pierdan los derechos de los socios trabajadores por una deficiente tramitación, producida en muchas ocasiones por no haber contemplado las especificidades previstas para los socios trabajadores de las Cooperativas de Trabajo Asociado o para los de trabajo en otras clases de cooperativas para el caso de los tuviese.

Consideramos que es ahora, debido al incremento de desempleo que se está produciendo por la crisis económica globalizada, que es cuando más se están demandando las prestaciones por desempleo (y no las de cese de actividad por su reciente aparición y que todavía no han generado prestaciones) aún cuando es cierto que afortunadamente la demanda de estas prestaciones por parte de los socios de las Cooperativas son inferiores a las del resto de los trabajadores de otras configuraciones societarias.

Así pues solamente pretendemos que este artículo sea de utilidad, particularmente para quienes tengan que realizar los trámites para que se reconozcan a los socios trabajadores o de trabajo de las Cooperativas, que estén adscritos en el régimen general o en el régimen especial de trabajadores autónomos, respectivamente, su situación legal de desempleo o el cese de actividad, aun cuando lo que realmente nos gustaría es que no se tuviese que utilizar por la plena ocupación de todas las personas con edad para prestar su trabajo, si bien somos conscientes que esto es un buen deseo que en estos momentos no sabemos cuándo se podrá conseguir, sobre todo si tenemos en cuenta las previsiones de desempleo para el año 2012.

Este artículo ha sido el resultado del trabajo de un equipo de personas especialistas en derecho y con una constatada especialidad en el ámbito cooperativo. 


\section{La prestación por desempleo en las cooperativas adscritas al Régimen General de la Seguridad Social}

Las Cooperativas de trabajo asociado que hubiesen optado por el Régimen de la Seguridad Social para sus socios trabajadores, así como los socios de trabajo de las demás clases de Cooperativas, tienen derecho a la prestación por desempleo, cuando estén en situación legal de desempleo.

Hay que precisar que solamente las Cooperativas de trabajo asociado pueden optar para sus socios trabajadores, en lo que se refiere al régimen de la seguridad social, entre el régimen general y el régimen especial de trabajadores autónomos, pues para los socios de trabajo no existe tal opción al tener preceptivamente y en todo caso la condición de asimilados a trabajadores por cuenta ajena, por lo que quedarían integrados en el régimen general (o en alguno de los regímenes especiales de la seguridad social, según proceda, de acuerdo con su actividad) todo ello a tenor de lo previsto en la Disposición Adicional Cuarta, de la Ley General de la Seguridad Social, aprobada por el Real Decreto Legislativo 1/1994, de 20 de junio (BOE 29/06/1994).

Por último tenemos que tener en cuenta que las cooperativas con socios de trabajo que, al amparo de la disposición transitoria séptima de la Ley 3/1987, de 2 de abril, General de Cooperativas, optaron por mantener la asimilación de sus socios de trabajo a trabajadores autónomos, a efectos de Seguridad Social, conservarán ese derecho de opción, si bien en el caso de que con posterioridad a la fecha de entrada en vigor de la Ley 27/2009, de 30 de diciembre, de medidas urgentes para el mantenimiento y el fomento del empleo y la protección de las personas desempleadas (BOE 31/12/2009), esto es a partir del 1 de enero de 2010, la cooperativa modificara el régimen de encuadramiento de sus socios de trabajo, para su incorporación como trabajadores por cuenta ajena, en el régimen que corresponda, no podrá volver a ejercitar el derecho de opción, tal y como se determina en la Disposición Adicional decimoséptima, de la Ley 20/2009, que modifico el apartado 2 de la disposición adicional cuarta de la Ley General de la Seguridad Social.

A continuación vamos ya a entrar a ver tanto la regulación de la prestación por desempleo para los socios trabajadores y de trabajo adscritos al Régimen General de la Seguridad, como a los diferentes supuestos de la prestación por desempleo y su tramitación. 


\subsection{Regulación}

La normativa específica, sobre la prestación por desempleo para las Cooperativas con socios trabajadores o de trabajo adscritos al régimen general de la seguridad social, lo integran dos Reales Decretos que se relacionan a continuación:

- Real Decreto 1043/1985, de 19 de junio, por el que se amplía la protección por desempleo a los socios trabajadores de Cooperativas de Trabajo Asociado (en lo sucesivo RD 1043/1985).

- Real Decreto 42/1996, de 19 de enero, por el que se amplía la protección por desempleo a los socios trabajadores de cooperativas de trabajo asociado en situación de cese temporal o reducción temporal de jornada (en lo sucesivo RD 42/1996).

Durante muchos años, las Cooperativas que habían optado por encuadrar a sus socios trabajadores o de trabajo en el régimen general, como asimilados a trabajadores por cuenta ajena, no tenían derecho a la prestación por desempleo, y su reconocimiento, sobre todo en lo que se refiere a la cobertura de la prestación por desempleo para situaciones de carácter temporal, como las contempladas en el Real Decreto 42/1996, fue debido a la constante reivindicación del Movimiento Cooperativo, tanto a nivel de Euskadi como del resto de Comunidades Autónomas de España, como muestra de ello, quizás es significativa la publicación del libro « La desprotección relativa por desempleo de los socios de Cooperativas de Trabajo Asociado: una discriminación no razonable» cuyos autores fueron Narciso Paz Canalejo y Jesús R. Mercader Ugina, editada por la Federación de Cooperativas de Trabajo Asociado de Euskadi, en el año 1993, en la que se cuestionaba de forma rotunda la no cobertura de la prestación por desempleo en situaciones de carácter temporal, y ya tres años más tarde, se aprueba el citado Real Decreto 42/1996.

Asimismo, los supuestos que se contemplan en ambos Reales Decretos han sido objeto de múltiples modificaciones a lo largo del tiempo, si bien en nuestro artículo vamos a solamente a centrarnos en la redacción actual de ambas disposiciones.

1.2. Supuestos de desempleo que dan lugar a la prestación por desempleo a los socios trabajadores o de trabajo de las cooperativas y forma de acreditarlas para no perjudicar dicha prestación

Para que los socios trabajadores o de trabajo puedan percibir la prestación por desempleo es necesario que se encuentren en una situación legal de desempleo. 
Se encuentran en situación legal de desempleo los socios trabajadores o de trabajo, encuadrados en el Régimen General o en algunos de los regímenes especiales que protejan la contingencia de desempleo, que estén inmersos en alguno de los supuestos contemplados en el artículo 2 del Real Decreto 1043/1985 y en el artículo 1 del Real Decreto 42/1996, que se reproducen en los cuadros siguientes:

Supuestos de situación legal de desempleo, con cese definitivo de la prestación de trabajo

Por expulsión improcedente de la Cooperativa.

Por causas económicas, tecnológicas o de fuerza mayor.

Por finalización del período al que se limitó el vínculo societario de duración determinada.

Los aspirantes a socios que hubieran cesado en la prestación de trabajo durante el período de prueba por decisión unilateral del órgano de administra-

Art. 2.2 RD 1043/1985 ción de la Cooperativa.

Supuestos de situación legal de desempleo, con cese temporal o parcial de la prestación de trabajo, por causas económicas, tecnológicas o de fuerza mayor

Cuando los socios, hubieren cesado, con carácter temporal, en la prestación de trabajo en la cooperativa, con la consiguiente privación de los anticipos laborales acreditables por dicha prestación.

Cuando se reduzca temporalmente su jornada de trabajo, al menos en una tercera parte, siempre que los anticipos laborales derivados directamente de dicha prestación sean objeto de la análoga reducción y que la jornada reducida resultante no sea superior a veintiséis horas semanales en cómputo anual.
Artículo y normativa

Art. 2.1.a) RD 1043/1985

Art. 2.1.b) RD 1043/1985

Art. 2.1.c) RD 1043/1985 


\section{SUPUESTOS DE CESE DEFINITIVO EN LA COOPERATIVA}

1. No superar el socio trabajador o de trabajo el periodo de prueba a criterio del órgano de administración (ya sea consejo rector/ administrador único/administradores solidarios o mancomunados)

La declaración de la situación legal de desempleo se efectuará mediante la comunicación del acuerdo adoptado por el órgano de administración de la Cooperativa, de no admisión como socio trabajador o de trabajo por no haber superado el periodo de prueba.

- Acreditación de esta situación de desempleo: la comunicación que el órgano de administración hace al aspirante a socio trabajador o de trabajo, de no admisión por no superar el periodo de prueba.

- Tramitación: Los socios trabajadores o de trabajo, de forma individual deben presentar su solicitud de desempleo, dentro del plazo de 15 días siguientes a la notificación del órgano de administración, del acuerdo de la no admisión como socio por no haber superado el periodo de prueba, aportando la citada comunicación.

2. Cuando el socio trabajador o de trabajo haya sido expulsado de forma improcedente

En este caso para que se declare la situación legal de desempleo es precisa la notificación del acuerdo de expulsión improcedente por parte del órgano de administración, con la fecha de efectos, o, en su caso, un acta de conciliación judicial o la resolución definitiva de la jurisdicción social declarando, en ambos supuestos, la improcedencia de la expulsión.

Así pues la acreditación de esta situación de desempleo se puede realizar mediante la aportación de cualquiera de los documentos siguientes:

1. La notificación del acuerdo de expulsión, adoptado por el órgano de administración, en la que se refleje de forma expresa su improcedencia y la fecha de efectos.

Esta forma de acreditar la situación legal de desempleo merece una reflexión. «Con esta vía, el RD 1043/1985, está posibilitando al órgano de administración de la Cooperativa que pueda reconocer, de forma expresa la improcedencia de la expulsión de un socio trabajador así como la fecha de efectos», con lo que el socio afec- 
tado, si está conforme con el acuerdo adoptado por el citado órgano social no tiene que recurrirlo ante la Asamblea General.

Tenemos que tener en cuenta que esta vía podría abrir, en caso de un uso no adecuado del mismo, la exigencia de responsabilidades para los administradores de las Cooperativas, piénsese por ejemplo que se le reconoce la improcedencia y se le abonan indemnizaciones desmesuradas, ciertamente de ello hay que dar cuenta a los socios de la Cooperativa, y estos pueden ejercer acciones de responsabilidad contra los administradores cuando sus acuerdos no estén debidamente fundamentados, sobre todo en lo que se refiere a las indemnizaciones por tener una repercusión directa en la cuenta de explotación de la Cooperativa y por lo tanto en los resultados de la misma.

En todo caso, esta modalidad se está utilizando poco, ya que lo habitual es que el órgano de administración adopte el acuerdo de expulsión y que la Asamblea General sea la que lo ratifique o revoque, tras la interposición del correspondiente recurso por parte del socio afectado, todo ello sin menoscabo de que en vía judicial, ya sea mediante acuerdo entre las partes, conseguido de forma previa al inicio del proceso, en un acta de conciliación judicial en la que se reconozca la improcedencia de la expulsión o mediante resolución judicial firme en la que se reconozca dicha improcedencia.

Por otra parte debe tenerse presente que si el acuerdo del órgano de administración no reconoce la improcedencia de la expulsión, el socio para no perjudicar su derecho a la prestación por desempleo y a las indemnizaciones que le correspondan, deberá recurrir dicho acuerdo ante la Asamblea General, pues en caso de no hacerlo, el acuerdo de los administradores sería firme y por lo tanto la expulsión no sería improcedente, con lo cual no estaríamos ante un supuesto legal de desempleo y por ello no tendría lugar a la prestación contributiva de desempleo del Servicio de Empleo Público Estatal (SEPE) ni a indemnización alguna por parte de la Cooperativa.

En todo caso de la redacción actual del apartado a) del art. 3 del RD 1043/1985, dada por la disposición adicional tercera de la Ley 45/2002, de 12 de diciembre, de medidas urgentes para la reforma del sistema de protección por desempleo y mejora de la ocupabilidad, no existe duda alguna para que sea suficiente la acreditación de la situación de desempleo con la notificación del órgano de administración de su acuerdo de expulsión y de su calificación expresa, como improcedente, con la fecha de efectos del mismo. 
Reproducción literal del apartado a), art. 3 del RD 1043/1985, en su versión inicial y la actual:

\begin{tabular}{cc}
\hline \multicolumn{1}{c}{ Redacción inicial } & \multicolumn{1}{c}{ Redacción actual } \\
\hline «a) En el supuesto de expulsión del & \multicolumn{1}{c}{ «a) En el supuesto de expulsión del } \\
socio será necesaria la resolución judicial & socio será necesaria la notificación del \\
definitiva de la jurisdicción competente & acuerdo de expulsión por parte del con- \\
que declare expresamente la improce- & sejo rector de la cooperativa, indicando \\
dencia de la expulsión.» & $\begin{array}{l}\text { su fecha de efectos, o, en su caso, el } \\
\text { acta de conciliación judicial o la resolu- } \\
\text { ción definitiva de la jurisdicción compe- } \\
\text { tente que declare expresamente la im- } \\
\text { procedencia de la expulsión.» }\end{array}$ \\
\hline
\end{tabular}

2. Acta de conciliación judicial, en la que se reconozca la improcedencia de la expulsión

3. Resolución firme de la jurisdicción de lo social, en la que se reconozca la improcedencia de la expulsión

Tramitación: Los socios trabajadores o de trabajo, de forma individual deben presentar su solicitud de desempleo, dentro del plazo de 15 días siguientes a la fecha de la notificación del acuerdo de expulsión improcedente, o, en su caso, del acta de conciliación judicial o de la resolución judicial declarando improcedente la expulsión.

3. Cuando el contrato de sociedad del socio trabajador o de trabajo se extinga de forma definitiva por causas económicas, tecnológicas o de fuerza mayor

En este supuesto, para que se declare la situación legal de desempleo es necesario contar con la Resolución de la Autoridad Laboral, en la que se constate la concurrencia de la causa alegada, así como la fecha de efectos, previos los trámites administrativos, que se exponen a continuación.

El procedimiento administrativo se inicia ante la Autoridad Laboral, mediante escrito, que suele tener forma de solicitud, y que tiene que ser cumplimentada por los representantes de la Cooperativa, esto es por su órgano de administración, previo acuerdo adoptado al efecto por la Asamblea General, para proceder a la extinción de los contratos de sociedad y por tanto de la prestación del trabajo de los so- 
cios trabajadores de la Cooperativa afectados (cese definitivo de los socios trabajadores: sin menoscabo de su derecho a la reincorporación en el plazo de dos años a contar desde la fecha de su baja obligatoria en la cooperativa y a su derecho al reembolso inmediato de sus aportaciones al capital social, tal y como se les reconoce en el párrafo segundo del apartado 2, del artículo 103, de la Ley 4/1993, de Cooperativas de Euskadi) y además se acompañan al escrito/solicitud la documentación siguiente:

- Un certificado literal del acuerdo de la extinción de los contratos de sociedad de los socios trabajadores o de trabajo adoptado por la Asamblea General, de los socios afectados, así como su causa/s.

- Relación de los socios afectados y en su caso de los trabajadores por cuenta ajena afectados.

- Memoria de la causa/s de desempleo. Debe tenerse en cuenta que en el RD 1043/1985 solo se consideran como tales las económicas, tecnológicas o de fuerza mayor, y no se relacionan las organizativas o productivas, como se precisa en el apartado 2 del artículo 103 de la Ley 4/1993, de 24 de junio, de Cooperativas de Euskadi o en el Estatuto de los Trabajadores en sus artículos 49.1.i, 51.1 y 52.c).

- Si fuese por causas económicas deberán aportarse los balances y cuentas de pérdidas y ganancias de los 3 últimos años.

- Y un informe de los aspectos financieros, productivos, comerciales y organizativos de la cooperativa.

- Plan provisional de acciones empresariales para la recuperación del empleo elaborado por el órgano de administración de la Cooperativa.

Tramitación: Se realiza ante la Autoridad Laboral competente (Delegación Territorial de Empleo del respectivo Territorio Histórico o la Dirección de Trabajo si la Cooperativa tuviese centros de trabajo en varios Territorios Históricos o provincias, tal como se determina en el apartado 1 del art. 4 del RD 1043/1985). La Autoridad Laboral deberá dictar en el plazo de treinta días una resolución en la que declarara, de haber constatado la concurrencia de la/s causa/s alegada/s, la situación legal de desempleo de los socios trabajadores y la fecha de efectos.

Previamente, deberá contar con el informe preceptivo elaborado por la Inspección de Trabajo y de la Seguridad Social (vid., apartado 5 del art. 4 del RD 1043/1985).

También puede pedir informes a los organismos que considere oportuno (vid., apartado 5 del art. 4 del RD 1043/1985). 
Los socios trabajadores o de trabajo, de forma individual deben presentar su solicitud de desempleo, dentro del plazo de 15 días siguientes a la notificación de la resolución de la Autoridad Laboral, en la que se reconozca la situación legal de desempleo y su fecha de efectos.

4. Cuando el contrato de sociedad de duración determinada de un socio trabajador o de trabajo concluya por finalización de su plazo

La situación legal de desempleo se acredita con la certificación expedida por los administradores de la Cooperativa, fijando que la causa de su cese en la cooperativa se produce por la finalización del vínculo societario y concretando de forma expresa su fecha de efectos.

- Acreditación de esta situación de desempleo: Mediante la certificación del órgano de administración en la que consta la baja del socio en la cooperativa por la finalización del periodo fijado en el contrato de sociedad de duración determinada y su fecha de efectos.

Tramitación: Los socios trabajadores o de trabajo, de forma individual deben presentar su solicitud de desempleo, dentro del plazo de 15 días siguientes a la fecha en que finalizó el periodo de su contrato de duración determinada, aportando la certificación del órgano de administración que lo acredite.

\section{SUPUESTOS DE CESE TEMPORAL O PARCIAL EN LA COOPERATIVA}

1. Cuando el contrato de sociedad del socio trabajador o de trabajo se suspenda temporalmente por causas económicas, tecnológicas o de fuerza mayor

En este supuesto, para que se declare la situación legal de desempleo es necesario contar con la Resolución de la Autoridad Laboral, en la que se constate la concurrencia de la causa alegada, así como la fecha de efectos, previos los trámites administrativos, que se exponen a continuación.

El procedimiento administrativo se inicia ante la Autoridad Laboral, mediante escrito, que suele tener forma de solicitud, y que tiene que ser cumplimentada por los representantes de la Cooperativa, esto es por su órgano de administración, previo acuerdo adoptado al efecto por la Asamblea General, para proceder a la suspensión de los contratos de sociedad y por tanto de la prestación del trabajo de los 
socios trabajadores de la Cooperativa afectados y además se acompañan al escrito/solicitud la documentación siguiente:

- Un certificado literal del acuerdo de suspensión total y temporal adoptado por la Asamblea General, de los socios afectados, así como su causa.

- Un certificado del Secretario con el visto bueno del Presidente (o del Administrador Único; o de un Administrador Solidario o de los Administradores Mancomunados) sobre la duración de la jornada de trabajo y su distribución horaria, de los socios afectados.

- Relación de los socios afectados y en su caso, relación de los trabajadores por cuenta ajena afectados.

- Memoria de la causa/s de desempleo. Debe tenerse en cuenta que en el RD 42/1996 solo se consideran como tales las económicas, tecnológicas o de fuerza mayor, y no se relacionan las organizativas o productivas, como se precisa en el apartado 2 del artículo 103 de la Ley 4/1993, o en el Estatuto de los Trabajadores en sus artículos 45.1.j) y 47.

- Si fuese por causas económicas deberá aportarse los balances y cuentas de pérdidas y ganancias de los 3 últimos años.

- Un informe de los aspectos financieros, productivos, comerciales y organizativos de la cooperativa.

- La justificación de la duración de la suspensión solicitada.

- Un plan provisional de acciones empresariales para la recuperación del empleo elaborado por el órgano de administración de la Cooperativa y aprobado por la Asamblea General.

A dicho plan se acompañara, a propuesta de la Inspección de Trabajo y Seguridad Social, de una propuesta de su seguimiento periódico, que tiene que realiza la Autoridad Laboral.

Tramitación: Se realiza ante la Autoridad Laboral competente (Delegación Territorial de Empleo del respectivo Territorio Histórico o la Dirección de Trabajo si la Cooperativa tuviese centros de trabajo en varios Territorios Históricos o provincias, tal como se determina en el apartado 1 del art. 4 del RD 1043/1985). La Autoridad Laboral deberá dictar en el plazo de treinta días una resolución en la que declarara, de haber constatado la concurrencia de la/s causa/s alegada/s, la situación legal de desempleo de los socios trabajadores y la fecha de efectos.

Previamente, deberá contar con el informe preceptivo elaborado por la Inspección de Trabajo y de la Seguridad Social (vid., apartado 5 del art. 4 del RD 1043/1985). 
También puede pedir informes a los organismos que considere oportuno (vid., apartado 5 del art. 4 del R.D. 1043/1985).

Los socios trabajadores o de trabajo, de forma individual deben presentar su solicitud de desempleo, dentro del plazo de 15 días siguientes a la notificación de la resolución de la Autoridad Laboral, en la que se reconozca la situación legal de desempleo y su fecha de efectos.

2. Cuando se reduzca temporalmente la jornada de trabajo del socio trabajador o de trabajo, por causas económicas, tecnológicas o de fuerza mayor

En este supuesto, para que se declare la situación legal de desempleo es necesario contar con la Resolución de la Autoridad Laboral, en la que se constate la concurrencia de la causa alegada, así como la fecha de efectos, previos los trámites administrativos, que se exponen a continuación:

El procedimiento administrativo se inicia ante la Autoridad Laboral, mediante escrito, que suele tener forma de solicitud, y que tiene que ser cumplimentada por los representantes de la Cooperativa, esto es por su órgano de administración, previo acuerdo adoptado al efecto por la Asamblea General, para proceder a la suspensión parcial de los contratos de sociedad y por tanto de la prestación del trabajo de los socios trabajadores de la Cooperativa afectados y además se acompañan al escrito/solicitud la documentación siguiente:

- Un certificado literal del acuerdo de suspensión parcial y temporal adoptado por la Asamblea General, de los socios afectados, así como su causa, que debe afectar al menos en una tercera parte de su jornada de trabajo, con análoga reducción de sus anticipos laborales. La reducción de jornada resultante no podrá ser inferior a las 26 horas/semana computadas de forma anual.

- Un certificado del Secretario con el visto bueno del Presidente (o del Administrador Único; o de un Administrador Solidario o de los Administradores Mancomunados) sobre la duración de la jornada de trabajo y su distribución horaria de los socios afectados.

- Relación de los socios afectados, y en su caso, relación de trabajadores por cuenta ajena afectados.

- Memoria de la causa/s de desempleo. Debe tenerse en cuenta que el RD 42/1996 solo se consideran como tales las económicas, tecnológicas o de fuerza mayor, y no se relacionan las organizativas o productivas, como se precisa en el apartado 2 del ar- 
tículo 103 de la Ley 4/1993, o en el Estatuto de los Trabajadores en sus artículos 45.1.j) y 47.

- Si fuese por causas económicas deberá aportarse los balances y cuentas de pérdidas y ganancias de los 3 últimos años.

- Un informe de los aspectos financieros, productivos, comerciales y organizativos de la cooperativa.

- La justificación de la reducción de jornada para la suspensión solicitada.

- Un plan provisional de acciones empresariales para la recuperación del empleo elaborado por el órgano de administración de la Cooperativa y aprobado por la Asamblea General.

A dicho plan se acompañara, a propuesta de la Inspección de Trabajo y Seguridad Social, de una propuesta de su seguimiento periódico, que tiene que realiza la Autoridad Laboral.

Tramitación: Se realiza ante la Autoridad Laboral competente (Delegación Territorial de Empleo del respectivo Territorio Histórico o la Dirección de Trabajo si la Cooperativa tuviese centros de trabajo en varios Territorios Históricos o provincias, tal como se determina en el apartado 1 del art. 4 del RD 1043/1985). La Autoridad Laboral deberá dictar en el plazo de treinta días una resolución en la que declarara, de haber constatado la concurrencia de la/s causa/s alegada/s, la situación legal de desempleo de los socios trabajadores y la fecha de efectos.

Previamente, deberá contar con el informe preceptivo elaborado por la Inspección de Trabajo y de la Seguridad Social (vid., apartado 5 del art. 4 del RD 1043/1985).

También puede pedir informes a los organismos que considere oportuno (vid., apartado 5 del art. 4 del RD 1043/1985).

Los socios trabajadores o de trabajo, de forma individual deben presentar su solicitud de desempleo, dentro del plazo de 15 días siguientes a la notificación de la resolución de la Autoridad Laboral, en la que se reconozca la situación legal de desempleo y su fecha de efectos.

\subsection{Impresos}

Están a disposición de los interesados en las Delegaciones Territoriales de Empleo sitas en Araba, Bizkaia y Gipuzkoa en las direcciones siguientes:

- Araba: C/ Samaniego, 2-2.․ 01008 Vitoria-Gasteiz. Tfno: 945-0170 30. 
—Bizkaia: C/ Gran Vía, 85. 48011. Bilbao.

Tfno: 94-403 1216 y 944-03 1239.

- Gipuzkoa: C/ Intxaurrondo, 70-2. a. 20015 Donostia. Tfno: 943-0170 30.

Asimismo, se pueden bajar de la pagina web del Departamento de Empleo y Asuntos Sociales del Gobierno Vasco www.gizartelan.ejgv. euskadi.net y en su ventana de Trabajo y Relaciones Laborales, en el apartado gestiones y trámites, y en el subapartado de impresos y trámites para realizar tus gestiones, están los impresos de regulación de empleo.

Como es evidente con dichos impresos deben acompañarse, los documentos específicos de las cooperativas, para cada uno de los supuestos susceptibles de regulación de empleo para los socios trabajadores o de trabajo de las Cooperativas y en su caso de sus trabajadores por cuenta ajena.

En todo caso, debe tenerse en cuenta, que a la fecha de elaborar este artículo, los impresos que están en la página web antes referenciada van a ser modificados por la reforma laboral de 2012 y si bien para las Cooperativas no tiene mucha importancia en lo que se refiere a sus socios trabajadores, dicha reforma sí afecta a la regulación de empleo para los trabajadores por cuenta ajena que tengan, pero al no ser objeto de nuestro estudio no la abordamos, si bien dejamos constancia de ello porque los citados impresos y sus instrucciones tendrán que adaptarse a la aludida reforma laboral 2012 y en consecuencia como ya comentábamos se modificaran en breve.

\subsection{Sentencias de interés sobre esta materia}

Se pueden localizar en el buscador de Jurisprudencia del Consejo General del Poder Judicial denominado CENDOJ cuyo enlace es el siguiente: http://www.poderjudicial.es/search/indexAN.jsp

Del mismo modo se pueden localizar en otras bases de datos, como Aranzadi, la Ley, Tirant on line, entre otras.

En anexo a este artículo se recoge una relación de referencias de sentencias.

Asimismo, es muy interesante el artículo que la profesora titular de la Facultad de Derecho de Granada, de Trabajo y Seguridad Social, Sofía Olarte Encabo, titulado «Formalismo ante la situación legal de desempleo, de socios trabajadores de cooperativa de trabajo asociado: la parcial desprotección por desempleo en situaciones paradójicas, en relación con la sentencia del Tribunal Supremo, Sala 4. ${ }^{\text {a }}$ del 16 de mayo 
de 2005, publicado en la revista Temas Laborales, núm. 82/2005, páginas 237-248.

1.5. Recomendaciones para mejorar la regulación de la prestación por desempleo de los socios trabajadores o de trabajo de las cooperativas

Tras la elaboración de los apartados precedentes se estimaba oportuno reflexionar y realizar aportaciones para una posible mejora o perfeccionamiento de la actual regulación.

Y fruto del análisis y reflexión se plantearon recomendaciones de carácter procedimental y sustantivo.

\section{RECOMENDACIÓN DE MEJORA PROCEDIMENTAL}

Se consideran desproporcionadas e innecesarias ${ }_{L}$ especialmente en las Cooperativas de dimensión reducida, en los supuestos en los que los contratos de sociedad de los socios se extingan de forma definitiva, temporal o parcial, por causas económicas, tecnológicas o de fuerza mayor, la aportación y elaboración de los documentos siguientes:

- Informe de los aspectos financieros, productivos, comerciales y organizativos de la cooperativa.

- Plan provisional de acciones empresariales para la recuperación del empleo elaborado por él órgano de administración de la cooperativa.

Se consideran innecesarias ya que la causa alegada se debe acreditar en la memoria y con la aportación, en el supuesto de causas económicas, con la aportación de los balances y cuentas de pérdidas y ganancias de los últimos 3 años.

\section{RECOMENDACIONES DE CARÁCTER SUSTANTIVO}

1. ${ }^{\text {a }}$ Se estima que existe una situación no protegida para los socios trabajadores o trabajo, en lo que se refiere a la expulsión procedente, y consideramos que es una exclusión que no tiene ninguna justificación, por lo que se debería posibilitar su inmediata cobertura

Con ello lo que se pretende es que los socios trabajadores o de trabajo que fuesen expulsados de forma procedente, tengan acceso a la prestación por desempleo. 
Ciertamente esta recomendación, y más en estos momentos, debería rodearse de las máximas cautelas, para evitar que se malinterprete, y para ello, máxime teniendo en cuenta la relación societaria de los socios trabajadores y de trabajo, quizás lo mejor sería que para ello fuese preciso que así se declarase de forma expresa mediante Sentencia, si bien en este caso se le estaría obligando al socio tener que agotar la vía interna de la Cooperativa, aun cuando estuviese de conforme con el acuerdo adoptado por el órgano de administración, lo cual ciertamente no deja de ser paradójico.

2. ${ }^{\text {a }}$ Para el supuesto de que la primera recomendación no fuese atendida se debería plantear la reducción del tipo de cotización por desempleo, tanto para las Cooperativas como para los socios trabajadores o de trabajo, habida cuenta que no tienen cobertura por la prestación por desempleo en el caso de expulsión procedente

Parece lógico que el tipo de cotización no sea igual cuando no se tiene la misma protección, y de hecho las cotizaciones por ejemplo de los socios trabajadores o de trabajo de duración determinada tienen un tipo de cotización superior al indefinido idéntico al de los trabajadores por cuenta ajena de duración determinada.

\section{La prestación por cese de actividad a los socios de las cooperativas de trabajo asociado encuadrados en el Régimen Especial de los Trabajadores por Cuenta Propia o Autónomos o en el Régimen Especial de los Trabajadores del Mar}

\subsection{Normativa reguladora}

Ley 32/2010, de 5 de agosto, por la que se establece un sistema específico de protección por cese de actividad de los trabajadores autónomos (BOE 06/08/2010), en lo sucesivo utilizaremos la expresión Ley $32 / 2010$.

Real Decreto 1541/2011, de 31 de octubre, por el que se desarroIla la Ley 32/2010, de 5 de agosto, por la que se establece un sistema específico de protección por cese de actividad de los trabajadores autónomos (BOE 01/10/2011), en lo sucesivo utilizaremos la expresión RD 1541/2011. 


\subsection{Prestaciones}

Nosotros solo nos vamos a centrar en la prestación económica por cese total, temporal o definitivo, de la actividad de los socios trabajadores de cooperativas de trabajo asociado que hubiesen optado por el encuadramiento del Régimen Especial de de los trabajadores por cuenta propia o autónomos o en el régimen especial de los trabajadores del mar.

No obstante, tenemos que tener en cuenta la previsión introducida por la Disposición adicional quincuagésima primera, de la Ley 27/2011, de 1 de agosto, sobre actualización, adecuación y modernización del sistema de Seguridad Social, ya que en base a ella, dicha protección por cese de actividad no es de aplicación a los socios de las Cooperativas que cuenten de un sistema intercooperativo de prestaciones sociales, complementario al Sistema Público, que establezca un nivel de cobertura, en lo que respecta a las situaciones de cese de actividad, al menos equivalente al regulado en la Ley 32/2011, como es el caso de las Cooperativas que tienen socios encuadrados en el Régimen Especial de los Trabajadores por Cuenta Propia o Autónomos y que están en Lagun-Aro, Entidad de Previsión Social Voluntaria.

A continuación reproduzco la citada disposición:

Disposición adicional quincuagésima primera. Modificación del ámbito subjetivo de protección de la Ley 32/2010, de 5 de agosto, por la que se establece un sistema específico de protección por cese de actividad de los trabajadores autónomos.

Se introduce un nuevo apartado 3 en el artículo 2, con el siguiente texto:

3. La protección por cese de actividad no resultará obligatoria en el caso de socios de Cooperativas comprendidos en el Régimen Especial de los Trabajadores por Cuenta Propia o Autónomos, siempre que estas Cooperativas dispongan de un sistema intercooperativo de prestaciones sociales, complementario al Sistema Público, que establezca un nivel de cobertura, en lo que respecta a las situaciones de cese de actividad, al menos equivalente al regulado en la presente Ley.

2.3. Supuestos legales de cese de actividad y acreditación de los mismos

Se regulan en la Disposición Adicional Sexta, de la Ley 32/2010, y se acreditarán aportando los documentos, según el supuesto, relacionados en el apartado 2, del artículo 10, del RD 1541/2011. 


\section{A) Supuestos legales}

a) Los que hubieren cesado, con carácter definitivo o temporal, en la prestación de trabajo y, por tanto, en la actividad desarrollada en la cooperativa, perdiendo los derechos económicos derivados directamente de dicha prestación por alguna de las siguientes causas:

1. a Por expulsión improcedente de la cooperativa.

2. ${ }^{a}$ Por causas económicas, técnicas, organizativas, productivas o de fuerza mayor.

3. ${ }^{a}$ Por finalización del período al que se limitó el vínculo societario de duración determinada.

4. ${ }^{a}$ Por causa de violencia de género, en las socias trabajadoras.

5. ${ }^{a}$ Por pérdida de licencia administrativa de la cooperativa.

b) Los aspirantes a socios en período de prueba que hubieran cesado en la prestación de trabajo durante el mismo por decisión unilateral del Consejo Rector u órgano de administración correspondiente de la cooperativa.

\section{B) ACREDITACIÓN DE LOS SUPUESTOS}

\section{Expulsión improcedente del socio}

En el supuesto de expulsión improcedente del socio, en los términos expresados en la disposición adicional sexta de la Ley 32/2010 y el apartado 2.a) del RD 1541/2011.

Será necesario acreditarlo mediante la aportación de los documentos siguientes:

a) la notificación del acuerdo de expulsión por parte del Consejo Rector de la cooperativa u órgano de administración correspondiente, indicando su fecha de efectos, y

b) en todo caso el acta de conciliación judicial o la resolución definitiva de la jurisdicción competente que declare expresamente la improcedencia de la expulsión.

Estamos en este supuesto igual que en la redacción dada inicialmente en apartado a) del artículo 3 del RD 1043/1985, lo cual no deja de ser cuanto menos curioso, por no decir que supone una clara contradicción y previsiblemente una omisión del legislador no deseada, a tenor de lo actualmente previsto en la citada disposición en la que se posibilita el acuerdo de expulsión por parte del Consejo Rector y su calificación como improcedente, sin embargo ello no es po- 
sible en el Régimen Especial de Autónomos, pues en él el órgano de administración solo puede adoptar el acuerdo de expulsión, y será el Juzgado el que determine, ya sea en vía conciliación o sentencia, su improcedencia.

2. Cese definitivo o temporal de la actividad por motivos económicos, técnicos, organizativos o de producción

En el caso de cese definitivo o temporal de la actividad por motivos económicos, técnicos, organizativos o de producción, en los términos expresados en el artículo 5.1.a) de la Ley 32/2010 y en el artículo 4.1 del RD 1541/2011.

Nota: No se exigirá el cierre de establecimiento abierto al público en los casos en los que no cesen la totalidad de los socios trabajadores de la cooperativa de trabajo asociado.

Tales supuestos se acreditarán mediante la aportación, por parte de la sociedad cooperativa de la siguiente documentación:

a) Una declaración jurada a la que habrán de acompañarse, en función del motivo alegado, los documentos de carácter

a. contable,

b. profesional,

c. fiscal,

d. administrativo o

e. judicial,

en los que se hará constar la fecha de producción de los referidos motivos.

b) Asimismo, se deberá acompañar una certificación literal del acuerdo de la Asamblea General o, en su caso, del órgano de administración, del cese definitivo o temporal de la prestación de trabajo y de actividad de los socios trabajadores, con la relación de los socios que deben causar baja en la Cooperativa.

3. Cese definitivo o temporal de la actividad por fuerza mayor

En el caso de cese definitivo o temporal de la actividad por fuerza mayor, en los términos expresados en el artículo 6.1.b) de la Ley 32/2010 y en el artículo 5 del RD 1541/2011.

Será necesaria que la existencia de tales causas sea debidamente constatada por el órgano gestor de la prestación. 
Órgano Gestor:

- Regla General: La Mutua de Accidentes de Trabajo y Enfermedades Profesionales de la Seguridad Social con la que tengan cubierta la protección dispensada a las contingencias derivadas de accidentes de trabajo y enfermedades profesionales.

- Reglas especiales: En el supuesto de trabajadores autónomos que tengan cubierta la protección dispensada a las contingencias derivadas de accidentes de trabajo y enfermedades profesionales con una entidad gestora de la Seguridad Social, la tramitación de la solicitud y la gestión de la prestación por cese de actividad corresponderá:

a) En el ámbito del Régimen Especial de la Seguridad Social de los Trabajadores del Mar, al Instituto Social de la Marina.

b) En el ámbito del Régimen Especial de los Trabajadores por Cuenta Propia o Autónomos, al Servicio Público de Empleo Estatal.

Y será necesario acreditarla aportando al Órgano Gestor competente una declaración jurada a acompañada de los documentos que se relacionan a continuación:

1. Documentación en la que se detalle, por los medios de prueba que se estimen oportunos:

a) el suceso,

b) su naturaleza imprevisible, o previsible pero inevitable,

c) su relación con la imposibilidad de continuar con la actividad,

d) concretando si la fuerza mayor es determinante del cese definitivo o temporal, y en este último caso, su duración estimada,

e) así como cualquier otro aspecto que permita al Órgano Gestor declarar tal circunstancia (de fuerza mayor).

2. En la declaración jurada del órgano de administración de la Cooperativa, del cese temporal o definitivo, deberá reflejarse, la fecha de la producción de la fuerza mayor, y se adjuntaran los documentos relacionados en el punto 1 precedente. 
4. ${ }^{\circ}$ Cese definitivo por la finalización del periodo por el que se limito el vínculo societario de duración determinada

En el caso de cese definitivo por la finalización del periodo por el que se limito el vínculo societario de duración determinada, en los términos expresados en el apartado 2.d) de la disposición adicional sexta de la Ley 32/2010 y en el artículo 5 del RD 1541/2011.

Será necesario acreditarlo mediante la aportación de una certificación del Consejo Rector u órgano de administración correspondiente de la baja en la cooperativa por dicha causa y su fecha de efectos.

\section{Cese definitivo por causa de violencia de género en las socias trabajadoras}

En el caso de cese definitivo por causa de violencia de género en las socias trabajadoras, en los términos expresados en el apartado 2.e) de la disposición adicional sexta de la Ley 32/2010 y en los artículos 7 y 10.2e) del RD 1541/2011.

Será necesaria acreditarlo mediante solicitud en la que se incluirá:

a) Declaración escrita de haber cesado o interrumpido su trabajo, y en este último caso una duración estimada, así como la fecha en que se produce el cese o la interrupción.

b) Aportación de alguno de los documentos siguientes:

1. Auto de incoación de diligencias previas.

2. Auto acordando la adopción de medidas cautelares de protección a la víctima.

3. Auto acordando prisión provisional del detenido.

4. Auto de apertura de juicio oral.

5. La orden de protección.

6. Informe o escrito de acusación del Ministerio Fiscal.

7. Sentencia judicial condenatoria.

6. Cese durante el periodo de prueba

En el caso de cese durante el periodo de prueba, en los términos expresados en el apartado 2.f) de la disposición adicional sexta de la Ley 32/2010 y en el artículo 10.2.g) del RD 1541/2011.

Será necesaria acreditarlo mediante: La comunicación del acuerdo de no admisión por parte del Consejo Rector u órgano de administración correspondiente de la cooperativa al aspirante. 
7. Cese por revocación o extinción de la licencia administrativa concedida a la Cooperativa

En el caso de cese por revocación o extinción de la licencia administrativa concedida a la Cooperativa, en los términos expresados en el apartado 1.a).5 de la disposición adicional sexta de la Ley 32/2010 y en los artículos 6 y 10.2.f) del RD 1541/2011.

Se acreditará aportando: resolución de extinción de licencias, permisos o autorizaciones administrativas habilitantes para el ejercicio de la actividad, en la que conste:

a) Motivo de la extinción.

b) Fecha de efectos.

No se consideradas como causas acreditativas de este supuesto las siguientes:

— Cuando en la resolución se acredite que la pérdida de la licencia viene motivada por:

a) incumplimientos contractuales,

b) o por la comisión de infracciones, faltas administrativas o delitos imputables u

c) otros incumplimientos imputables a los socios para conseguir la pérdida voluntaria de la licencia.

\subsection{Requisitos de los socios para tener derecho a las prestaciones}

Se reconocerá el derecho a la prestación por cese de actividad, a los socios trabajadores de las Cooperativas de Trabajo Asociado, en los que concurran los requisitos siguientes:

a) Estar a la fecha del cese de actividad, afiliados, en situación de alta y cubiertas las contingencias profesionales y la de cese de actividad, en el Régimen Especial de los Trabajadores por Cuenta Propia o Autónomos, o al Régimen Especial de los Trabajadores del Mar en su caso.

b) Solicitar la baja a causa del cese de actividad, ya sea temporal o definitiva.

c) Tener cubierto el período de cotización de al menos 12 meses por cese de actividad.

d) Encontrarse en situación legal de cese de actividad.

e) Acreditar activa disponibilidad para la reincorporación al mercado de trabajo a través de las actividades formativas y de 
orientación profesional a las que pueda convocarle el Servicio Público de Empleo de la correspondiente Comunidad Autónoma (en nuestra CCAA Lanbide) o en su caso el Instituto Social de la Marina, mediante la suscripción del compromiso de actividad al que se refiere el artículo 231 del Real Decreto Legislativo 1/1994, de 20 de junio, por el que se aprueba el Texto Refundido de la Ley General de la Seguridad Social.

f) No haber cumplido la edad ordinaria para causar derecho a la pensión contributiva de jubilación, salvo que el trabajador autónomo no tuviera acreditado el período de cotización requerido para ello.

g) Hallarse al corriente en el pago de las cuotas a la Seguridad Social, en la fecha del cese de actividad. No obstante y si en la fecha del cese de actividad no se cumpliera con este requisito pero se tuviera cubierto el período mínimo de cotización para tener derecho a la protección, el órgano gestor invitará al trabajador autónomo a que, en el plazo improrrogable de treinta días naturales, ingrese las cuotas debidas, y lo acredite ante el órgano gestor, aportando certificado de la Tesorería General de la Seguridad Social de su abono.

\subsection{Duración de la prestación económica}

Se regula en el artículo 8 y Disposición Adicional Primera de la Ley 32/2010 y en el artículo 12, del RD 1541/2011.

Su duración es diferente según el periodo de cotización y la edad del socio trabajador a la fecha del cese, todo lo cual se plasma en el cuadro siguiente:

\begin{tabular}{lcc}
\hline Periodo cotización & Periodo protección & $\begin{array}{c}\text { Periodo protección } \\
\text { entre } 60 \text { y } 64 \text { años }\end{array}$ \\
\hline De 12 a 17 meses & 2 meses & 2 meses \\
De 18 a 23 meses & 3 meses & 4 meses \\
De 24 a 29 meses & 4 meses & 6 meses \\
De 30 a 35 meses & 5 meses & 8 meses \\
De 36 a 42 meses & 6 meses & 10 meses \\
De 43 a 47 meses & 8 meses & 12 meses \\
De 48 meses o más & 12 meses & 12 meses \\
\hline
\end{tabular}




\subsection{Base reguladora y cuantía de la prestación económica}

Se regula en el artículo 9, de la Ley 32/2010 y en el artículo 13, del RD 1541/2011:

1. La base reguladora de la prestación económica por cese de actividad será el promedio de las bases por las que se hubiere cotizado durante los doce meses continuados e inmediatamente anteriores a la situación legal de cese.

2. La cuantía de la prestación, durante todo su período de disfrute, se determinará aplicando a la base reguladora el 70 por ciento.

La cuantía máxima de la prestación por cese de actividad será:

— Regla general: del 175 por ciento del Indicador Público de Rentas de Efectos Múltiples (IPREM).

- Excepciones a la regla general:

a) Cuando el trabajador autónomo tenga un hijo a su cargo: 200 por ciento del IPREM.

b) Cuando el trabajador autónomo tenga dos o más hijos a su cargo 225 del IPREM.

La cuantía mínima de la prestación por cese de actividad será:

a) Del 80 por ciento del IPREM, cuando el trabajador autónomo no tenga hijo/s a su cargo.

b) Del 107 por ciento del IPREM, cuando el trabajador autónomo tenga hijo/s a su cargo.

Se entenderá que se tienen hijos a cargo, cuando éstos sean menores de veintiséis años, o mayores con una incapacidad en grado igual o superior al treinta y tres por ciento, carezcan de rentas de cualquier naturaleza iguales o superiores al salario mínimo interprofesional excluida la parte proporcional de las pagas extraordinarias, y convivan con el beneficiario.

A los efectos de la cuantía máxima y mínima de la prestación por cese de actividad, se tendrá en cuenta el Indicador Público de Rentas de Efectos Múltiples mensual, incrementado en una sexta parte, vigente en el momento del nacimiento del derecho.

\begin{tabular}{ccccc}
\hline Año & IPREM diario & IPREM mensual & $\begin{array}{c}\text { IPREM anual } \\
(12 \text { pagas })\end{array}$ & $\begin{array}{c}\text { IPREM anual } \\
(14 \text { pagas })\end{array}$ \\
\hline 2012 & $17,75 €$ & $532,51 €$ & $6.390,13 €$ & $7.455,14 €$ \\
\hline
\end{tabular}

Nota: El IPREM del año 2012, es el mismo que se fijo para el año 2011 por la Ley 39/2010, de 22 de diciembre, de Presupuestos Generales del Estado para 2011, ya que la aprobación de los Presupuestos Generales de 2012 ha sido aplazada por las últimas elecciones generales del año 2011. 
2.7. Supuesto que no tiene la consideración legal de cese de actividad $y$ efectos

Está regulado en el apartado 3, de la Disposición adicional Sexta, de la Ley 32/2010.

No estarán en situación legal de cese de actividad los socios trabajadores de las cooperativas de trabajo asociado que, tras cesar definitivamente en la prestación de trabajo, y por tanto, en la actividad desarrollada en la cooperativa, y haber percibido la prestación por cese de actividad, vuelvan a ingresar en la misma sociedad cooperativa en un plazo de un año, a contar desde el momento en que se extinguió la prestación.

Efectos: Si el socio trabajador reingresa en la misma sociedad cooperativa en el plazo señalado, deberá reintegrar la prestación percibida.

\subsection{Plazos para realizar la solicitud}

Se regulan en el artículo 16, de la Ley 32/2010 y en el artículo 11, del RD 1541/2011.

Los socios trabajadores que se encuentren en situación legal de cese de actividad deberán solicitar el reconocimiento del derecho a las prestaciones a la Mutua de Accidentes de Trabajo y Enfermedades Profesionales de la Seguridad Social con la que tengan cubiertas las contingencias de AT y EP, salvo lo establecido en la disposición adicional cuarta de la Ley 32/2010 y en párrafo segundo del apartado 1 del artículo 11 del RD 1541/2011, hasta el último día del mes siguiente a la declaración de la situación legal de cese de actividad.

En caso de presentar la solicitud fuera del indicado plazo, y reuniese todos los demás requisitos, se le descontaran del periodo de percepción los días que medien entre la fecha en que debió presentar la solicitud y la fecha en que se llevo a cabo.

2.9. Cumplimiento de garantías y de procedimientos por parte de la cooperativa

Se regulan en el apartado 5, de la Disposición Adicional Sexta, de la Ley 32/2010.

Cuando la cooperativa de trabajo asociado tenga a uno o más trabajadores por cuenta ajena, en el supuesto de cese total de la actividad de la cooperativa será requisito previo al cese de actividad de los socios 
trabajadores el cumplimiento de las garantías y procedimientos regulados en la legislación laboral.

\subsection{Tipo de cotización}

Se regula en el apartado 3, del artículo 14, de la Ley 32/2010.

Se fija en el 2,2\% de la base elegida en el RETA o en el Régimen Especial de los Trabajadores del Mar para los socios trabajadores de la Cooperativa.

\subsection{Jurisdicción competente}

Se regula en el artículo 19, de la Ley 32/2010.

Los órganos jurisdiccionales del orden social serán los competentes para conocer de las decisiones del órgano gestor, relativas al reconocimiento, suspensión, o extinción de las prestaciones por cese de actividad, así como al pago de las mismas.

Cabe también interponer reclamación previa ante el órgano gestor antes de acudir a la jurisdicción del orden social.

\subsection{Recomendaciones para mejorar la regulación de la prestación por cese de actividad los socios trabajadores}

Tras la elaboración de los apartados precedentes se estimaba oportuno reflexionar y realizar aportaciones para una posible mejora o perfeccionamiento de la actual regulación.

Y fruto del análisis y reflexión se plantearon recomendaciones de carácter procedimental y sustantivo.

\section{RECOMENDACIÓN DE MEJORA PROCEDIMENTAL}

Se consideran desproporcionadas e innecesarias, especialmente en las Cooperativas de dimensión reducida, en los supuestos en los que los contratos de sociedad de los socios se extingan de forma definitiva, temporal o parcial, por motivos económicos, técnicos, organizativos, de producción o de fuerza mayor, la aportación y elaboración de los documentos siguientes:

- que deben acompañarse en la declaración jurada, de carácter, contable, profesional, fiscal, administrativo o judicial. 
Se consideran innecesarios ya que los motivos por los que se pide la prestación por cese de actividad alegada se puede acreditar con la declaración jurada sin necesidad de aportar tales documentos o solamente aportando aquellos que sean necesarios.

\section{RECOMENDACIÓN DE CARÁCTER SUSTANTIVO}

Sería recomendable posibilitar que él órgano de administración de la Cooperativa pudiese calificar la expulsión como improcedente tal y como se establece en el apartado a) art. 3 del RD 1043/1985 en su versión actual.

No existe ninguna justificación para que su tratamiento tenga que ser diferente al previsto para los socios trabajadores adscritos al régimen general de la seguridad social, y con ello además se está creando una diferencia no justificada, por lo que parece razonable que la improcedencia de la expulsión pueda acreditase de manera idéntica o lo que lo mismo que el órgano de administración de una Cooperativa adscrita al Régimen Especial de Trabajadores Autónomos, puede calificar la expulsión como improcedente.

\section{Anexo de reseñas de sentencias de interés sobre la prestación por desempleo}

A continuación, procedo a relacionar algunas reseñas de sentencias de interés, sacadas del Fondo Documental del Consejo General del Poder Judicial, denominado CENDOJ, el 2 de marzo de 2012:

\section{ROJ: STS 3114/2005}

Tipo órgano: Tribunal Supremo. Sala de lo Social.

Municipio: Madrid (Sección: 1).

Ponente: Milagros Calvo Ibarlucea.

N. ${ }^{\circ}$ recurso: 3943/2003 (fecha: 16/05/2005).

Tipo resolución: Sentencia.

Resumen: Desempleo. Socio trabajador de cooperativa de trabajo asociada, cese definitivo por causas económicas, tecnológicas o de fuerza mayor. Necesidad de su constatación por la autoridad laboral. RD 1043/1985, de 19 de junio.

\section{ROJ: STSJ MAD 6322/2011}

Tipo órgano: Tribunal Superior de Justicia. Sala de lo Social.

Municipio: Madrid (Sección: 3).

N. ${ }^{\circ}$ recurso: 1722/2011 (fecha: 26/05/2011).

Tipo resolución: Sentencia. 


\section{ROJ: STSJ CAT 4071/2011}

Tipo órgano: Tribunal Superior de Justicia. Sala de lo Social.

Municipio: Barcelona (Sección: 1).

N. ${ }^{\circ}$ recurso: 1077/2010 (fecha: 05/04/2011).

Tipo resolución: Sentencia.

\section{ROJ: STSJ CL 5379/2010}

Tipo órgano: Tribunal Superior de Justicia. Sala de lo Social.

Municipio: Valladolid (Sección: 1).

N. ${ }^{\circ}$ recurso: 1347/2010 (fecha: 06/10/2010).

Tipo resolución: Sentencia.

Resumen: Desempleo.

\section{ROJ: STSJ PV 3585/2008}

Tipo órgano: Tribunal Superior de Justicia. Sala de lo Social. Municipio: Bilbao (Sección: 1).

N. ${ }^{\circ}$ recurso: 2438/2008 (fecha: 11/11/2008).

Tipo resolución: Sentencia.

\section{ROJ: STSJ MU 1256/2008}

Tipo órgano: Tribunal Superior de Justicia. Sala de lo Social.

Municipio: Murcia (Sección: 1).

N. ${ }^{\circ}$ recurso: 293/2008 (fecha: 26/05/2008).

Tipo resolución: Sentencia.

Resumen: Desempleo.

\section{ROJ: STSJ MU 584/2008}

Tipo órgano: Tribunal Superior de Justicia. Sala de lo Social. Municipio: Murcia (Sección: 1).

N. ${ }^{\circ}$ recurso: 183/2008 (fecha: 05/05/2008).

Tipo resolución: Sentencia.

Resumen: Desempleo.

\section{ROJ: STSJ CLM 3525/2007}

Tipo órgano: Tribunal Superior de Justicia. Sala de lo Social. Municipio: Albacete (Sección: 1).

N. ${ }^{\circ}$ recurso: 1603/2006 (fecha: 22/11/2007).

Tipo resolución: Sentencia.

Resumen: Desempleo. 


\section{ROJ: STSJ AR 1533/2006}

Tipo órgano: Tribunal Superior de Justicia. Sala de lo Social.

Municipio: Zaragoza (Sección: 1).

N. ${ }^{\circ}$ recurso: 1089/2006 (fecha: 27/12/2006).

Tipo resolución: Sentencia.

\section{ROJ: STSJ AR 1532/2006}

Tipo órgano: Tribunal Superior de Justicia. Sala de lo Social.

Municipio: Zaragoza (Sección: 1).

N. ${ }^{\circ}$ recurso: 1090/2006 (fecha: 18/12/2006).

Tipo resolución: Sentencia.

\section{ROJ: STSJ AR 1488/2006}

Tipo órgano: Tribunal Superior de Justicia. Sala de lo Social.

Municipio: Zaragoza (Sección: 1).

N. ${ }^{\circ}$ recurso: 972/2006 (fecha: 07/12/2006).

Tipo resolución: Sentencia.

\section{ROJ: STSJ AR 1480/2006}

Tipo órgano: Tribunal Superior de Justicia. Sala de lo Social.

Municipio: Zaragoza (Sección: 1).

N. ${ }^{\circ}$ recurso: 989/2006 (fecha: 07/12/2006).

Tipo resolución: Sentencia.

\section{ROJ: STSJ MU 379/2005}

Tipo órgano: Tribunal Superior de Justicia. Sala de lo Social.

Municipio: Murcia (Sección: 1).

N. ${ }^{\circ}$ recurso: 386/2005 (fecha: 25/04/2005).

Tipo resolución: Sentencia.

Resumen: Desempleo.

\section{ROJ: STSJ CAT 11296/2004}

Tipo órgano: Tribunal Superior de Justicia. Sala de lo Social.

Municipio: Barcelona (Sección: 1).

N. ${ }^{\circ}$ recurso: 8382/2003 (fecha: 14/10/2004).

Tipo resolución: Sentencia.

\section{ROJ: STSJ MAD 7034/2004}

Tipo órgano: Tribunal Superior de Justicia. Sala de lo Social.

Municipio: Madrid (Sección: 4).

N. ${ }^{\circ}$ recurso: 2669/2004 (fecha: 28/05/2004).

Tipo resolución: Sentencia. 


\section{ROJ: STSJ MU 924/2004}

Tipo órgano: Tribunal Superior de Justicia. Sala de lo Social. Municipio: Murcia (Sección: 1).

N. ${ }^{\circ}$ recurso: 456/2004 (fecha: 03/05/2004).

Tipo resolución: Sentencia.

Resumen: Desempleo.

\section{ROJ: STSJ MU 741/2004}

Tipo órgano: Tribunal Superior de Justicia. Sala de lo Social.

Municipio: Murcia (Sección: 1).

N. ${ }^{\circ}$ recurso: 348/2004 (fecha: 05/04/2004).

Tipo resolución: Sentencia.

Resumen: Desempleo.

\section{ROJ: STSJ MU 2427/2003}

Tipo órgano: Tribunal Superior de Justicia. Sala de lo Social. Municipio: Murcia (Sección: 1).

N. ${ }^{\circ}$ recurso: $1254 / 2003$ (fecha: 24/11/2003).

Tipo resolución: Sentencia.

Resumen: Desempleo.

\section{ROJ: STSJ CAT 1862/2003}

Tipo órgano: Tribunal Superior de Justicia. Sala de lo Social. Municipio: Barcelona (Sección: 1).

N. ${ }^{\circ}$ recurso: 2250/2002 (fecha: 11/02/2003).

Tipo resolución: Sentencia.

\section{ROJ: STSJ CV 8837/2002}

Tipo órgano: Tribunal Superior de Justicia. Sala de lo Social. Municipio: Valencia (Sección: 1).

N. ${ }^{\circ}$ recurso: 335/2002 (fecha: 18/09/2002).

Tipo resolución: Sentencia.

\section{ROJ: STSJ CAT 9507/2002}

Tipo órgano: Tribunal Superior de Justicia. Sala de lo Social.

Municipio: Barcelona (Sección: 1).

N. ${ }^{\circ}$ recurso: 8360/2001 (fecha: 30/07/2002).

Tipo resolución: Sentencia. 


\section{ROJ: STSJ ICAN 4141/2001}

Tipo órgano: Tribunal Superior de Justicia. Sala de lo Social. Municipio: Santa Cruz de Tenerife (Sección: 1).

N. ${ }^{\circ}$ recurso: 529/2001 (fecha: 14/11/2001).

Tipo resolución: Sentencia.

\section{ROJ: STSJ GAL 594/2001}

Tipo órgano: Tribunal Superior de Justicia. Sala de lo Social.

Municipio: Coruña (A) (Sección: 1).

N. ${ }^{\circ}$ recurso: 5192/1997 (fecha: 26/01/2001).

Tipo resolución: Sentencia.

\section{ROJ: STSJ CL 418/2001}

Tipo órgano: Tribunal Superior de Justicia. Sala de lo Social.

Municipio: Valladolid (Sección: 1).

N. ${ }^{\circ}$ recurso: 2390/2000 (fecha: 22/01/2001).

Tipo resolución: Sentencia.

\section{ROJ: STSJ CV 510/2001}

Tipo órgano: Tribunal Superior de Justicia. Sala de lo Social.

Municipio: Valencia (Sección: 1).

N. ${ }^{\circ}$ recurso: 4341/1997 (fecha: 19/01/2001).

Tipo resolución: Sentencia.

\section{ROJ: STSJ AND 20193/2000}

Tipo órgano: Tribunal Superior de Justicia. Sala de lo Social.

Municipio: Málaga (Sección: 1).

N. ${ }^{\circ}$ recurso: 994/2000 (fecha: 29/12/2000).

Tipo resolución: Sentencia.

\section{ROJ: STSJ AR 3015/2000}

Tipo órgano: Tribunal Superior de Justicia. Sala de lo Social.

Municipio: Zaragoza (Sección: 1).

N. ${ }^{\circ}$ recurso: 924/2000 (fecha: 18/12/2000).

Tipo resolución: Sentencia.

\section{ROJ: STSJ AND 14227/2000}

Tipo órgano: Tribunal Superior de Justicia. Sala de lo Social.

Municipio: Granada (Sección: 1).

N. ${ }^{\circ}$ recurso: 951/2000 (fecha: 04/10/2000).

Tipo resolución: Sentencia. 


\section{ROJ: STSJ AND 14223/2000}

Tipo órgano: Tribunal Superior de Justicia. Sala de lo Social. Municipio: Granada (Sección: 1).

N. ${ }^{\circ}$ recurso: 1018/2000 (fecha: 04/10/2000).

Tipo resolución: Sentencia.

\section{ROJ: STSJ AND 13706/2000}

Tipo órgano: Tribunal Superior de Justicia. Sala de lo Social.

Municipio: Málaga (Sección: 1).

N. ${ }^{\circ}$ recurso: 480/2000 (fecha: 29/09/2000).

Tipo resolución: Sentencia.

\section{ROJ: STSJ GAL 7283/2000}

Tipo órgano: Tribunal Superior de Justicia. Sala de lo Social.

Municipio: Coruña (A) (Sección: 1).

N. ${ }^{\circ}$ recurso: 3276/1997 (fecha: 23/09/2000).

Tipo resolución: Sentencia.

\section{ROJ: STSJ MU 2165/2000}

Tipo órgano: Tribunal Superior de Justicia. Sala de lo Social. Municipio: Murcia (Sección: 1).

N. ${ }^{\circ}$ recurso: 432/2000 (fecha: 10/07/2000).

Tipo resolución: Sentencia.

\section{ROJ: STSJ AND 9933/2000}

Tipo órgano: Tribunal Superior de Justicia. Sala de lo Social. Municipio: Sevilla (Sección: 1).

N. ${ }^{\circ}$ recurso: 4508/1999 (fecha: 29/06/2000).

Tipo resolución: Sentencia.

\section{ROJ: STSJ CL 3272/2000}

Tipo órgano: Tribunal Superior de Justicia. Sala de lo Social.

Municipio: Burgos (Sección: 1).

N. ${ }^{\circ}$ recurso: 396/2000 (fecha: 13/06/2000).

Tipo resolución: Sentencia.

\section{ROJ: STSJ AND 5828/2000}

Tipo órgano: Tribunal Superior de Justicia. Sala de lo Social.

Municipio: Sevilla (Sección: 1).

N. ${ }^{\circ}$ recurso: 3836/1998 (fecha: 14/04/2000).

Tipo resolución: Sentencia. 


\section{ROJ: STSJ AND 1350/2000}

Tipo órgano: Tribunal Superior de Justicia. Sala de lo Social.

Municipio: Sevilla (Sección: 1).

N. ${ }^{\circ}$ recurso: 4009/1999 (fecha: 28/01/2000).

Tipo resolución: Sentencia.

\section{ROJ: STSJ MAD 145/2000}

Tipo órgano: Tribunal Superior de Justicia. Sala de lo Social. Municipio: Madrid (Sección: 4).

N. ${ }^{\circ}$ recurso: 5627/1999 (fecha: 13/01/2000).

Tipo resolución: Sentencia.

\section{ROJ: STSJ CV 7141/1999}

Tipo órgano: Tribunal Superior de Justicia. Sala de lo Social.

Municipio: Valencia (Sección: 1).

N. ${ }^{\circ}$ recurso: 2151/1996 (fecha: 08/11/1999).

Tipo resolución: Sentencia.

\section{ROJ: STSJ AND 10757/1999}

Tipo órgano: Tribunal Superior de Justicia. Sala de lo Social. Municipio: Sevilla (Sección: 1).

N. ${ }^{\circ}$ recurso: 3687/1998 (fecha: 10/09/1999).

Tipo resolución: Sentencia.

\section{ROJ: STSJ AND 4371/1999}

Tipo órgano: Tribunal Superior de Justicia. Sala de lo Social.

Municipio: Sevilla (Sección: 1).

N. ․ recurso: 2881/1998 (fecha: 16/04/1999).

Tipo resolución: Sentencia.

\section{ROJ: STSJ CAT 2927/1999}

Tipo órgano: Tribunal Superior de Justicia. Sala de lo Social. Municipio: Barcelona (Sección: 1).

N. ${ }^{\circ}$ recurso: 7125/1998 (fecha: 18/03/1999).

Tipo resolución: Sentencia.

\section{ROJ: STSJ AND 1617/1999}

Tipo órgano: Tribunal Superior de Justicia. Sala de lo Social.

Municipio: Sevilla (Sección: 1).

N. ․ recurso: 1421/1998 (fecha: 25/02/1999).

Tipo resolución: Sentencia. 
Se finaliza este artículo, el 6 de marzo de 2012, por parte de Fco. Javier Sanz Santaolalla, para su análisis por parte de la Comisión de la AIDC 2012, de la Universidad de Deusto.

Posteriormente tras la sesión de la Comisión Técnica de la AIDC, que tuvo lugar el 17 de mayo de 2012, se incluyeron las correcciones y mejoras que se plantearon en la misma y posteriormente se perfecciono con las sugerencias y aportaciones que se hicieron por sus miembros a la versión final, que se publica en este Boletín. 